\title{
Controlling Homeless People? Power, Interventionism and Legitimacy
}

\author{
BETH WATTS*, SUZANNE FITZPATRICK** AND SARAH JOHNSEN*** \\ *I-SPHERE, Heriot-Watt University, William Arrol Building, Edinburgh, EH14 4AS \\ email: b.watts@hw.ac.uk \\ **I-SPHERE, Heriot-Watt University, William Arrol Building, Edinburgh, EH14 4AS \\ email: s.fitzpatrick@hw.ac.uk \\ ***I-SPHERE, Heriot-Watt University, William Arrol Building, Edinburgh, EH14 4AS \\ email: s.johnsen@hw.ac.uk
}

\begin{abstract}
There is intense debate over the legitimacy of interventions which seek behavioural change on the part of street homeless people. 'Hard' measures, such as arresting people for begging, are particularly controversial, but 'softer' interventions such as motivational interviewing have also prompted objections on grounds that they are paternalistic. At the same time, the 'non-interventionist' stance of some service providers has been accused of perpetuating harmful street lifestyles. Inspired by Ruth Grant's philosophically informed interrogation of the ethics of incentives, we propose a normative framework for application in this field. Via systematic exploration of Grant's three 'legitimacy standards' (legitimate purpose, voluntary response, effects on character), and an additional outcome-focussed fourth (effectiveness, proportionality and balance), we attempt to unsettle any intuitive assumption that noninterventionist approaches are necessarily more morally defensible than interventionist ones. We also, however, explicate the high ethical and empirical bar required to justify social control measures.
\end{abstract}

\section{Introduction}

A wealth of international literature narrates long-standing concerns about the legitimacy of interventions which seek to change the behaviour of street homeless people (Mitchell, 1997; Amster, 2003; Fitzpatrick and Jones, 2005; DeVerteuil et al., 2009; Johnsen and Fitzpatrick, 2010; Whiteford, 2010; Flint, 2009; Parsell, 2011; Bowpitt et al., 2014; Stuart, 2014; DeVerteuil, 2014). Interventions which involve elements of force, such as arresting people for begging or sleeping rough, are particularly controversial, condemned by many as 'criminalising' poor and vulnerable people (O'Sullivan, 2012). Beyond these 'hard' measures, there is also controversy over 'softer' forms of intervention which seek to persuade people to change their lifestyles, such as motivational interviewing (Wahab, 2005) and assertive outreach (Parsell, 2011), with some commentators arguing that they are paternalistic and patronising (Williamson, 2002). At the same time, there 
has been anxiety over the comparatively 'tolerant' agendas of 'unconditional acceptance' pursued by some services, such as soup runs, which have been accused of perpetuating harmful street lifestyles by making it 'easier' for people to live on the street (Randall and Brown; 2002; Shelter, 2005; National Law Centre on Homelessness and Poverty (NLCHP), 2014; Midgely, 2016). In short, this is an extraordinarily sensitive area which tends to polarise both academic and practitioner opinion, while being of significant international policy relevance.

This paper's primary aim is to propose a framework for evaluating the legitimacy of varying modes of power deployed to change the behaviour of street homeless people, with the empirical examples explored derived primarily from UK homelessness practice. More broadly, however, it seeks to offer a fresh normative perspective on long-running debates about the 'controlling' role of social policy interventions with vulnerable populations (Higgins, 1980; Harrison and Sanders, 2016) and to suggest a useful starting point for ethical analysis relevant across a range of both geographical and social policy contexts. Throughout the paper we draw on a conceptual and theoretical mapping exercise undertaken for a major programme of UK-based research ${ }^{1}$ assessing the efficacy and ethicality of social policy interventions designed to shape people's behaviour by making access to welfare goods conditional on conduct. This exercise sought to illuminate and critique potential ethical justifications for the wide-ranging forms of welfare conditionality now implemented across many parts of the world (Watts and Fitzpatrick, forthcoming).

The paper begins by conceptualising the forms of social control that have been employed in the UK and elsewhere in efforts to shape the conduct of street homeless people, before proposing a set of normative criteria against which to judge the legitimacy of these modes of 'power over' this highly vulnerable group. Building on Ruth Grant's (2002, 2006, 2012) philosophically-informed work on the ethics of incentives, we attempt to unsettle any intuitive assumption that non-interventionist approaches are necessarily more morally defensible than interventionist ones. We also seek to explicate the high bar that must be set for the ethical use of harder forms of social control and to clarify the empirical evidence that must be sought to defend such interventions.

\section{Conceptualising and evaluating interventionism in homelessness policy and practice}

People affected by street homelessness typically have long-term histories of poverty, disadvantage and trauma (Fitzpatrick, Bramley and Johnsen, 2013; Walter et al., 2016). Engagement in transgressive 'street culture' activities associated with rough sleeping, such as begging and street drinking (McNaughton Nicholls, 2009; Fitzpatrick et al., 2011), has increasingly been the focus of 'control' as well as 'care' measures that seek to foster engagement with support services and desistance 
from these activities (Dobson, 2011, 2015; Fitzpatrick and Johnsen, 2009; Johnsen et al., 2016; Midgley, 2016).

These social control interventions encapsulate various means of exerting power over the targeted population. Drawing on Bachrach and Baratz (1963), Lukes (2005), and Grant (2006), we distinguish between three forms of overt interventionism in the homelessness field which seek to alter individuals' behaviour by employing different modes of power. These are: 'force', wherein compliance is secured via the removal of the possibility of choosing not to comply (e.g. arresting people for begging, sleeping rough or associated activities); 'coercion', where compliance is ensured via the threat of deprivation (e.g. making access to accommodation conditional on signing up to a care or treatment plan); and 'influence', where compliance is sought via persuasive efforts to shape people's beliefs, judgements or behaviour (e.g. via intentionally directive 'motivational interviewing' techniques or 'assertive' forms of street outreach).

These explicitly interventionist modes of operation can be contrasted with non-interventionist approaches, which involve little or no overt attempt to secure behavioural change. A non-interventionist stance is generally characteristic of soup runs/kitchens, day centres and traditional night shelters, which are often (but not always) run by faith-based organisations, in the UK at least (Johnsen, 2014; Johnsen et al., 2005a, 2005b). Providers of such services seek to establish a context of 'non-judgemental sanctuary' and 'patient challenge' deemed to enable improvements in individuals' motivations and life circumstances (Bowpitt et al., 2014).

These contrasting approaches can be characterised as moving from 'hard' (force and coercion) to 'soft' (influence) to 'no' (tolerance) means of exerting power. Intuitively, it may seem that the harder forms of social control require the most robust ethical defence, with softer or non-interventionist approaches less morally problematic (Fitzpatrick and Jones, 2005). However, Ruth Grant (2006), a political scientist specialising in the normative study of 'incentives' (see also Grant, 2002, 2012), has criticised assessments of legitimacy by means of this simple hierarchy, observing that:

There are varieties of coercion as well as varieties of persuasion, and they are not all equally legitimate. The use of force includes the legitimate police powers of the state as well as tyranny; it includes a fair fight as well as overpowering the defenseless. Persuasion too is not a simple category. It includes demagoguery, begging, flattery, and fraud as well as rational conviction. (Grant, 2006: 31)

In place of such hierarchical assumptions, Grant identifies three primary criteria for judging the legitimacy of the deployment of power:

1. Whether it serves a legitimate purpose

2. Whether it allows for a voluntary response

3. By its effects on the character of the parties involved 
This framework was developed by Grant drawing on longstanding debates in political and moral philosophy spanning the work of the Greek philosophers (Sophocles, Plato, Aristotle); to seventeenth- and eighteenthcentury philosophers (Mandeville, Hobbes, Machiavelli); to the more recent contributions of Isaiah Berlin, Robert Nozick and Richard Titmuss (Grant, 2006). Other frameworks have been used to examine efforts to change the behaviour of rough sleepers. For instance, in this context, Midgely (2016) employs a feminist 'ethics of care' framework to explore the situated and relational basis of 'responsibility' - a concept core to debates about 'behaviour change'. More broadly, Deacon (2004) and White (2003) have brought philosophical tools to bear in examining the marked shift towards forms of welfare provision conditional on claimants' behaviour. We see Grant's framework as a valuable and distinct additional tool in this area, and as especially useful for our purposes given its focus on the ethicality of 'harder' and 'softer' deployments of power. As such, it can be fruitfully applied to the full range of social control mechanisms of interest here. Moreover, it introduces a welcome philosophically inspired rigour and logic into sometimes fraught and emotive social policy debates that can be conceptually and normatively 'fuzzy'. We would, however, add a fourth criterion to Grant's framework, which she hints at but does not fully develop, which focuses on the consequences of a specific exercise of power, that is:

4. Whether it is an effective, proportionate and balanced means to pursue the (legitimate) purpose(s) for which it is deployed

We examine each of these criteria in more detail below, proposing some modification and nuancing of the framework in its application to street homelessness policies.

\section{Legitimate purpose}

Core to Grant's approach is the necessity of identifying what counts as a legitimate purpose in the exercise of power. At first sight an apparently straightforward matter, this issue in fact brings in its wake a number of significant challenges, not least arbitrating between the 'multiple legitimate purposes' which may potentially compete or conflict with each other in any given policy arena (Berlin, 1969; Nagel, 1979). As Grant (2006) rightly argues, it is ethically insufficient that an exercise of power serves a legitimate purpose, if it simultaneously 'undermines a more important competing purpose' (2006: 36).

Relevant examples come easily to hand in the realm of street homelessness. For example, it is frequently argued in the US-centred 'criminalisation of homelessness' debate (NLCHP, 2014) that 'revanchist urbanism' seeks to satisfy the 'aesthetic' concerns of wealthy gentrifiers, with relevant authors clearly considering such 'sanitising' of the city a far from legitimate purpose (Smith, 1996; 
Webb, 2014). However, in a study encompassing several English cities, Fitzpatrick and Johnsen (2009) found that enforcement action on street homelessness and associated activities was usually prompted by ordinary local residents' concerns about, for example, human excreta and used hypodermic needles being regularly deposited in public areas. While these residents' motives for action were thus largely self-regarding, this does not necessarily make them unethical: it is at least prima facie reasonable for local residents to wish to see public health hazards addressed $^{2}$. If, however, the pursuit of this legitimate purpose were to engender a disregard for the well-being of the extremely vulnerable people engaged in street-based lifestyles, then the ethicality of these interventions could certainly be brought into question (Fitzpatrick and Johnsen, 2009).

Also relevant to the question of legitimacy of purpose is the issue of 'undue influence', wherein 'power which is legitimate in one sphere is used to gain power in an entirely different sphere' (Grant, 2006: 36). We interpret this as pertaining to the scope of legitimate action: is it the role of government, or for that matter, charitable services, to attempt to alter rough sleepers' behaviour? Or do such interventionist stances represent an overstepping of the mark? Should it remain an individual choice (or even 'right') to sleep rough (Housing Justice, 2008; Parsell, 2011), constrained only in circumstances where harm is being done to others (Mill, 1860)? Such concerns resonate with Foucauldian critiques of the behaviour change agenda, as an exercise in 'normalising' conduct according to dominant 'rationalities' (Jones et al., 2013). It is also reflected in the 'nonjudgemental' stance taken by some homelessness organisations in the face of street homeless people's 'lifestyle choices' (Cloke et al., 2005; Johnsen, 2014).

However, we find these sorts of liberty-based contentions far from compelling in the context of the life-limiting nature of the harms associated with street-based lifestyles (Fitzpatrick and Johnsen, 2009; Morrison, 2009; Parsell, 2011). Overwhelming evidence attests to the stigma, humiliation, violence, abuse and very poor health endured by people involved in activities such as begging and street drinking (Fitzpatrick and Johnsen, 2009; Morrison, 2009; Parsell, 2011). Moreover, it is clear that sleeping rough is very rarely, if ever, a lifestyle choice in any real sense. Rough sleepers tend to be a group with multiple barriers to resettlement (Parsell, 2011; Fitzpatrick et al., 2013), and the accommodation options available to them, such as hostels and night shelters, can be perceived as even more intimidating and threatening than sleeping on the streets (Fitzpatrick and Jones, 2005; Cloke et al., 2010; Parsell et al., 2014). Recognition of this latter point has been a major motivation for the development of scatter-site 'Housing First' programmes as an alternative to traditional congregate forms of homeless accommodation (Busch-Geertsema, 2013).

To be clear, our purpose thus far is not to argue that any specific social control intervention seeking to stop people sleeping rough is ethically justified, but simply to establish that as a purpose it is a legitimate one. We now move on 
to the other normative standards, staying with the theme of choice in the next section.

\section{Voluntariness}

Grant's (2002) core objective in her work on incentives is to establish that, contrary to the prevailing view in much economics literature, 'voluntariness of response' is not the sole criterion for judging the legitimacy of exercises of 'power over' other people. She also makes the crucial point that voluntariness can be interpreted in different ways, and that to 'have a choice' is not the same as 'to act autonomously'. Autonomy here is understood as the 'capacity to set one's own ends or purposes according to some rational standard' (Grant, 2006: 34 ) or, as Bothfield and Betzelt (2013) put it, the 'fundamental capacity for selfdetermination' (2013: 251). This accords with Isaiah Berlin's renowned insight that: '. . . the mere existence of alternatives is not . . enough to make my action free (although it may be voluntary) in the normal sense of the word' (1969: 130).

However, we feel that Grant (2006) fails to fully recognise the implications of this conceptual shift from voluntarism (narrowly understood) to autonomy when she condemns 'paternalistic' interventions as negating individual agency and dignity by: 'treating another person as if he is incapable of recognising for himself what his ends ought to be' (2006:34). This is to go with the grain of current public and academic debate, wherein the pejorative connotations of paternalism are so strong that it can seem almost impossible to mount a reasoned defence of any kind (Parsell and Marston, 2016). But we agree with Gregory (2015) that it may be time to reconsider the legitimacy of some specific kinds of paternalism, at least as applied to very vulnerable groups such as street homeless people. As he has recently argued:

... with adults ... there should indeed be a presumption of individual autonomy. But this is still not to say that paternalistic judgement is never appropriate. A common example is adult addiction and substance abuse. We would of course want to intervene in a way that maximises the recipient's control and dignity - but we also do in fact sometimes know what is better for him. Great care is needed in such cases. Ongoing judgement, reflection and dialogue will be crucial. But complete disavowal of 'paternalistic' responsibility for others - strangers as well as intimates - looks more like a moral abnegation rather than respectful distance. (Gregory, 2015: 345)

Parsell and Marston (2016) likewise make a case for 'justifiable paternalism' in the case of supportive housing interventions for people who have experienced chronic homelessness. They argue that such interventions represent a form of 'weak' paternalism in that they do not seek to change the goals of those who have experienced chronic homelessness, but rather: 'to intervene to change the behaviours of tenants so that they can achieve ends that they would, in a situation 
housed with security and the capacity for reflection, choose for themselves' (2016: 213).

We would go a step further than Parsell and Marston, and contend that it is possible, in principle, to justify even 'strong' forms of paternalism (that explicitly seek to alter someone's goals) in carefully defined circumstances. Bothfield and Betzelt's (2013) definition of autonomy helps to illuminate those circumstances:

The main criterion for autonomous decision making... is that individuals are capable of pursuing aims and projects, reflecting their own preferences and refraining from their immediate needs, feelings and spontaneous ideas... their capacity to figure out the 'authentic' motives for their decisions ... is the major condition for autonomy (2013: 252)

Rough sleepers suffering from severe addiction and/or mental ill health are an obvious case in point, where their ability to exercise autonomy so defined is severely compromised by the debilitating effects of these conditions on their cognitive capacity to make decisions and/or look toward the future (Epel et al., 1999; Sullivan et al., 2010). Also relevant is the distinction drawn (originally by Frankfurt, 1971) between first- and second-order preferences, the latter being 'wants about wants' emerging from reflective self-evaluation. The potential for divergence between 'ephemeral' and 'settled' preferences has likewise been explored (Goodin, 1995; Thomas and Buckmaster, 2010), and underpins, for instance, the development of voluntary exclusion agreements that enable problem gamblers to exclude their future self from entering betting shops. Emerging from this literature is a notion of free will rather different from the unproblematic 'pure form' that is often assumed (Harris, 2012), and best understood in terms of people's capacity to bring their multiple, fluid and potentially conflicting preferences closer together (Baggini, 2015).

While this is clearly contentious territory, we are also guided by Lukes' (2005) influential 'three-dimensional' view of power that rests on the insight that people will not always be aware of their 'real interests', which may depart in quite fundamental ways from their 'subjective preferences' (see also Watts, 2014). This gap may open up for a range of reasons, including the personal and temporal issues discussed above, but also due to domination or manipulation by powerful groups. Women's endorsement of norms of purity, modesty and self-abnegation in strongly patriarchal or religious cultures is an important example (Lukes, 2005; Nussbaum, 2000). Some homeless people's internalisation of 'blame' for their (structurally-driven) circumstances and 'acquiescent' orientation to services is another example, closer to the theme of this paper (Watts, 2014). At the same time, however, and in line with the critiques of free will discussed above, Lukes acknowledges that people's interests are 'many, conflicting and of different kinds' (2005: 147) and therefore argues that what counts as a 'real interest' should be ' $a$ function of one's explanatory purpose, framework and methods, which in turn have to be justified' (2005: 148). 
This means finding a defensible empirical basis for any external ascription of 'interests' to people. Lukes approaches this task by asking: 'what are the necessary conditions for human beings to flourish?' (2005: 117). He argues that the most promising contemporary account of these conditions is the 'capabilities approach' (Sen, 1992; Nussbaum, 2000), which focuses on the 'substantive freedom' that people enjoy to achieve 'valuable functionings' in key aspects of their lives. The priority for capability theorists is the 'actual opportunities' a person has what they are able to be or do - irrespective of whether they choose to exercise them. Nussbaum $(1992,2000)$ posits a list of philosophically derived 'central capabilities' that, she argues, all humans require to live a good life, including life, bodily integrity, health and control over one's environment. While the capabilities approach espoused by Nussbaum might be seen as paternalistic in externally identifying a set of valuable functionings ascribed to all human beings (and criticised or defended as such), proponents respond by emphasising that it seeks explicitly to allow for the diversity of people's life plans and circumstances, and aims to maximise their freedom to pursue their own version of 'the good life'. McNaughton Nicholls (2010) has used Nussbaum's framework to consider the role of housing in enabling (and constraining) a 'well lived life' in a qualitative study of transitions through homelessness in the UK (see also Tanekenov et al., 2017).

The core question this discussion raises is whether (paternalistic) restriction in short-term freedom of action can be demonstrated to restore, or establish, at least a basic level of personal autonomy for vulnerable adults in circumstances where this would otherwise be absent or threatened (see also Caplan, 2008; Lunze et al., 2016). If the answer is yes, deployment of interventionist approaches might legitimately be used to safeguard people's future (minimum) capabilities. Seen in this light, allowing a rough sleeper with a chaotic substance misuse problem to 'voluntarily choose' whether they engage with support may become ethically problematic, even indefensible, if it risks leaving them in extremely harmful situations, to the severe detriment of their longer-term autonomy, and in service to a simplistic notion of free will that is hard to defend.

\section{Character}

Grant's third legitimacy criterion concerns whether a particular deployment of power undermines the 'virtues' associated with good character:

Power relationships can have an impact on the character of all of the individuals involved in any particular interaction: both those who are engaged in making an offer, persuading, or threatening force and those who are responding to offers, argument or threats. (2012: 52)

One key consideration might be the impact of involvement in specific kinds of social control activities on the 'institutional culture' of service provider organisations (Gregory, 2015). The argument has been made that, under the 
banner of interventionism, some homelessness organisations have become simply a 'tool' or 'arm' of government, losing sight of their ethos, values and need for independence (Buckingham, 2011). Particularly for faith-based organisations, adaptation to secular and Government agendas has sometimes been argued to represent unacceptable 'mission drift', even amounting to 'functional atheism' (Greer and Horst, 2014).

Leaving aside one's position regarding the religious tenets of faith-based organisations (Johnsen and Fitzpatrick, forthcoming), there is a fundamental question of whose interests take precedence here (Fitzpatrick and Johnsen, 2009). This is an issue both of empathy (Gregory, 2015) and social justice (Fitzpatrick and Jones, 2005). To take an analogous example, if one identifies more strongly with the (powerless) recipient rather than the (powerful) giver in the context of charitable giving, one tends to feel less comfortable with the norm of charity than if the reverse is the case. The humiliation of the supplicant (Fitzpatrick et al., 2016), who is unable to honour the highly valued norm of reciprocity (Spicker, 1984), is a far less enticing prospect than the warm glow of 'moral selving' that can be enjoyed by the benefactor (Allahyari, 2000). Likewise, if one's sympathies lie predominantly with homeless people (the 'consumers' of welfare), rather than the faith-based organisations and other charities (the 'producers' of welfare), one is likely to be more concerned with the impact of an intervention on the intended beneficiary, particularly on their material and social circumstances, rather than on the character of the benefactor. An undue emphasis on the latter could, from this perspective, be considered ethically dubious, even self-indulgent.

Equally, however, Grant's framework raises the issue of the impact of social control mechanisms on the character of the homeless people directly targeted, regardless of their behavioural (non) responses to such interventions. According to Grant (2006) 'it makes an ethical difference, both for individual character and for social norms, whether people are motivated by fear of punishment, desire for reward, generosity, or rectitude, and so forth' (33). She argues that not only what we do, but why we do it, has a bearing on moral character and consequences. If, for example, you create a reliance on the extrinsic motivation of an incentive to entice people to do the 'right thing' - for example, giving blood, in Titmuss's (1997) classic example - you risk crowding out intrinsic, altruistic motivations.

In the context of rough sleeping, this raises the question of what difference it makes why a rough sleeper 'comes inside': are long-term outcomes better if the individual 'buys into' the need to change their lifestyle, rather than being forced or coerced into doing so? According to 'self-determination' theory, intrinsic motivation is associated not just with better 'performance' against the goal sought but also with enhanced health and well-being, by virtue of meeting people's fundamental psychological needs for competence and autonomy (Deci and Ryan, 2008). Persuasion may thus be argued to have the 
advantage over force or coercion, intended as it is to influence beliefs as well as behaviours (Grant, 2012). On the other hand, there is evidence in the case of enforcement-based responses to homelessness that the 'shock' of such interventions can sometimes provide a motivational prompt, which heightens 'readiness to change' and offers a window of opportunity that may never appear with more 'liberal' approaches that rely on the persuasive powers of outreach workers (Johnsen and Fitzpatrick, 2010), or on rough sleepers making a spontaneous decision to engage with support (Fitzpatrick and Jones, 2005). Such matters lie at the heart of the controversy concerning interventionist and noninterventionist forms of homelessness provision, and raise important empirical as well as ethical issues, as highlighted in the next section.

\section{Effectiveness, proportionality and balance}

Grant's standards of legitimacy are largely about (good) intentions (legitimate purpose) and (fair) process (voluntariness of response). While her focus on character impacts reflects a concern with the practical effects of deployments of power in one rather narrow sense, we would argue that a much broader consequentialist focus on (just) outcomes is a key additional legitimacy test for both interventionist and non-interventionist approaches. Grant touches on this point but does not explicitly develop it into one of her primary criteria, whereas we would give it priority, and probably precedence, over both voluntariness and impact on character, at least within the context of street homelessness policies, for the reasons now elaborated (see also Fitzpatrick and Johnsen, 2009).

The opprobrium drawn by paternalistic interventions noted above arises because such interventions infringe the key liberal principle that people are best placed to know their own interests (New, 1999) and certainly, with regard to adults, there should always be a 'presumption of individual autonomy' (Gregory, 2015: 345). For us it follows that all deployments of power that restrict a person's freedom of action, on grounds of their own best interests, require substantive, outcome-focussed justification. As Grant observes, this requires a judgement of the effectiveness of these modes of social control in meeting the required goal relative to the available alternatives. Developing this point, we propose that it is necessary to make a three-pronged positive case that:

a) the particular exercise of social control is likely to produce the desired (legitimate) result (i.e. it is effective);

b) that it is more likely to produce this result than other, less controlling, alternatives (i.e. it is proportionate); and

c) any unintended (negative) consequences are outweighed by the benefits likely to be accrued by the intervention (i.e. it strikes an appropriate balance) ${ }^{3}$. 
In our view, the meeting of all three of these sub-criteria is a necessary (though not sufficient) condition for the ethical deployment of social control measures with street homeless and other vulnerable populations. This stance can be illustrated via two UK-based case studies from either end of the social control spectrum discussed above.

First, from the 'force' end, we take the exemplar case of Anti-Social Behaviour Orders (ASBOs) and, more recently, Criminal Behaviour Orders (CBOs). These civil orders, intended to protect the public from behaviour that causes 'harassment, alarm or distress', have been used to control street culture activities like begging and street drinking in a number of UK cities (Johnsen et al., 2016). A breach of ASBO/CBO conditions is a criminal offence carrying the sanction of up to five years imprisonment. The deployment of such measures to achieve the (legitimate) aim of preventing people engaging in damaging street lifestyles can only be ethically pursued where it can be shown that their use is likely to be effective in achieving this aim or, at the very least, there is some plausible prospect of success. However, even if one assumes, for the sake of argument, that this effectiveness sub-criteria is satisfied, the use of ASBOs/CBOs remains unjustified within our proposed framework if less controlling (more proportionate) means of achieving the same aim are available. Finally, after satisfaction of both the effectiveness and proportionality sub-criteria, it is still necessary, we would argue, to show that any negative unintended or spill-over effects of the deployment of ASBOs in these circumstances are not so serious as to outweigh their benefits.

This last sub-criterion is particularly difficult to satisfy with respect to the use of ASBOs and other enforcement mechanisms in the context of street homelessness, given evidence of the displacement of some of the street homeless people targeted into potentially more risky activities (e.g. from begging into acquisitive crime or sex work) and more remote urban spaces (away from support services) (Fitzpatrick and Johnsen, 2009; Johnsen et al, 2016). More broadly, harder forms of interventionism risk an array of other unintended consequences including spill over effects (potentially fuelling feelings of personal failure, apathy, resignation, anxiety, stress) and scar-effects (e.g. resistance among the targeted group) (Watts and Fitzpatrick, forthcoming), thus damaging relationships with the services most likely to be able to help (Fitzpatrick and Johnsen, 2009). Such approaches may also foster stigmatising public attitudes of the target group as 'undeserving' and/or transgressive, undermining policy efforts to address their needs (Bastalgi, 2008; Fernandez Evangelista and Jones, 2013).

Our proposed normative framework thus sets a very high bar for the ethical use of hard enforcement measures like ASBOs. One can envisage circumstances where all of these sub-criteria are met, and indeed there are documented instances where the use of ASBOs/CBOs has 'saved lives' where they have 
been targeted on entrenched rough sleepers for whom all other attempts to assist them via softer interventions, combined with intensive and tailored support, had comprehensively failed (Johnsen and Fitzpatrick, 2010; Johnsen et al., 2016). Equally, however, it is clear that in a number of English cities ASBOs have been deployed without first pursuing more supportive interventions (Johnsen et al., 2016). It is exceedingly difficult in such circumstances to argue that they are an effective, proportionate and balanced 'last resort' intervention.

Our second example falls at the opposite end of the social control spectrum, and is that of soup runs, day centres and traditional night shelters which offer open door, 'unconditional' access to basic forms of support (Cloke et al., 2010). It is our contention that the effectiveness and balance (though not proportionality) sub-criteria discussed in this section apply equally to these tolerant approaches as to those employing greater degrees of social control. While intuitively it may appear that such non-interventionist services, even if ineffective at resolving homelessness, can at least do little harm, this is in fact highly contested territory (Johnsen, 2014). Whether such approaches have unintended consequences, and in particular whether they perpetuate damaging street lifestyles (Randall and Brown; 2002; Shelter, 2005; NLCHP, 2014), and in so doing erode rather than enhance personal autonomy, is an ethically important question meriting empirical investigation.

In particular, it is not safe to assume that because the motives of those involved - to offer support, hospitality and sanctuary to people in need are manifestly legitimate (Bowpitt et al., 2014; Cloke et al., 2005, 2010), the outcomes are necessarily ethical (Fitzpatrick and Johnsen, 2009). One key benefit of incorporating a consequentialist dimension within our framework is to allow for ethical judgements about the costs of inaction, or non-intervention, alongside those of intervention ${ }^{4}$. In this vein, Lancione (2014) is critical of a tendency among some scholars to accept and depict 'unconditional acceptance of the other' as necessarily 'good' in the absence of evidence about its effects. Relevant here is Bowpitt et al.'s (2014) account of non-interventionist day centres as both 'places of sanctuary' and 'places of change' where homeless people can be challenged by the creation of 'an atmosphere of welcome, friendliness and trust, in which the underlying damage of multiple exclusion can start to be addressed' (2014: 1265). They found that service users commended these day centres as 'among the most acceptable services on offer and frequently the only ones which [they] felt able to use or from which they had not been excluded' (2014: 1259). Providers of non-interventionist food services in Midgely's (2016) research presented their role as one of empathically 'taking care of rough sleepers in 'convivial spaces' where they were able to 'extend friendship' (621) in contradistinction to the 'responsibilising' orientation of commissioned services. Similar points were made by Cloke et al. (2010) regarding the role of non- 
interventionist services in generating localised geographies of compassion and care.

We would offer two cautionary comments in response to such observations. First, whether such services are in fact 'a vehicle for change' is a question of empirically measureable outcomes, not a question settled by an exploration of the intentions of the staff, or even the views of current users of the service. Second, the a priori rejection of explicitly directive encouragement and other interventionist models may, at least arguably, limit opportunities to explore the space between people's first- and second-order desires, as described above, and thus to safeguard the future autonomy of people sometimes facing life-threatening challenges. All this goes to highlight the critical importance of examining (tangible medium and longer-term) outcomes, as well as intentions and short-term experiences, in assessing matters of legitimacy.

\section{Concluding remarks}

Our starting point in this paper was the need for a robust normative framework to assess the legitimacy of interventions which attempt to alter the behaviour of street homeless people, in light of the ongoing controversy about their use in a range of advanced welfare economies, not least the UK (Johnsen, 2016). We have considered the range of modes of power deployed in efforts to exert social control over this group, including force, coercion and influence, as well as their counterpoint in non-interventionist (or 'tolerant') approaches. We found Grant's (2006) three criteria for judging the legitimacy of deployments of power, developed in the context of her investigation of incentives, very instructive. To her three primary criteria (legitimacy of purpose, voluntariness of response, and effects on character) we added a fourth, outcome-focused criterion (pertaining to effectiveness, proportionality and balance). As Grant acknowledges, her three criteria can conflict with each other (as indeed they can with our fourth) and judgements might vary over which ought to take precedence. In Grant's view, and ours, such judgements ought to take account of context, and it is therefore in relation to street homelessness policies that we draw the following substantive conclusions.

First, voluntariness and effect on character, while morally relevant, should be of a lower priority than legitimacy of purpose and, especially, effectiveness, proportionality and balance, in assessing the legitimacy of social control interventions in the homelessness field. This is because of the high risk of substantial (even life-threatening) harm to a very vulnerable group of people if they are left to make entirely 'voluntary' choices. Second, paternalistic interventions - which recognise that vulnerable people are not always able, at least in the short-term, to act in accordance with their 'settled' or 'authentic' preferences - are defensible if they are shown to prevent harms that may otherwise 
cause irreparable damage to someone's longer-term capacity to act autonomously (see also Caplan, 2008). Third, autonomy in this context can be understood in terms of the central capabilities that everyone needs to live a 'well lived' life (of their choice) (Nussbaum, 2000).

A critical implication of this analysis is that 'tolerant' approaches that do not explicitly seek to change behaviour in a directive manner need to be brought within the same ambit of ethical evaluation as forceful, coercive and persuasive interventions. They should not be assumed to be ethically unproblematic simply because terms like 'unconditional acceptance' sound innocuous. Assessed according to the framework proposed here, some tolerant approaches will be considered ethically justifiable and others will not-depending on the legitimacy of their purpose(s) and whether they are effective (or at least neutral) in safeguarding personal autonomy in the long run - in precisely the same way as more interventionist approaches. At a minimum, the possibility that tolerant approaches may inadvertently act to erode vulnerable people's longerterm autonomy must be given due consideration.

At the same time, it should be evident that our proposed framework sets a very high bar for the ethical use of hard forms of social control like ASBOs/CBOs. Our proposed normative criteria are exacting - especially with regard to whether any given hard intervention can be considered an effective, proportionate and balanced 'last resort' measure to safeguard the well-being and autonomy of the vulnerable individuals it targets. Examples in English cities where these criteria have not been met have, rightly, proven highly controversial. Serious consideration must also be given to the reasons why vulnerable homeless people may be reluctant to 'come indoors'. Alongside the debilitating cognitive effects of substance misuse and severe mental ill-health, it may be that the 'offer' is so unattractive - to stay in highly institutionalised, restrictive and intimidating large-scale hostels or shelters - that one may find some people's decision to sleep rough comprehensible, albeit highly regrettable, given the manifest dangers that it entails. Here the appropriate response is to improve the offer in an effort to persuade (rather than force) people to come inside.

There are thus essential empirical as well as normative considerations relevant in determining the legitimacy of interventionist and non-interventionist approaches to street homelessness. A priori arguments or emotional intuitions are insufficient in this field, with the matter most appropriately determined, we would argue, based on the range of ethical criteria set out above, and with primacy given to the justness or otherwise of the demonstrable outcomes of contrasting interventions.

\section{Acknowledgements}

We would like to express our sincere thanks to Sam Thomas (Making Every Adult Matter coalition) for his generous and insightful comments on an earlier draft of this article. We would also like to thank two anonymous reviewers and the journal editors for their guidance. 
The support of the Economic and Social Research Council (ESRC) under grant number $\mathrm{ES} / \mathrm{Ko0} 2163 / 2$ is gratefully acknowledged.

\section{Notes}

1 The collaborative project 'Welfare Conditionality: Sanctions, Support and Behaviour Change' (2013-2018) is funded under the Economic and Social Research Council's Centres and Large Grants Scheme. See www.welfareconditionality.ac.uk.

2 Scanlon and Adlam (2008) explore the psychosocial complexities that may underpin society's 'reasonable' wish to manage 'the other' and their detritus.

3 Though all negative consequences are relevant here, note that impacts on vulnerable people will weigh very heavily in the balance compared to those on non-vulnerable individuals given the 'high stakes' referred to elsewhere in this paper.

4 We are very grateful to Sam Thomas (Making Every Adult Matter) for drawing this point to our attention, alongside the many other incisive comments he made on an earlier draft of this paper.

\section{References}

Allahyari, R. (2000), Visions of Charity: Volunteer Workers and Moral Community, Berkeley: University of California Press.

Amster, R. (2003), 'Patterns of exclusion: sanitising space, criminalising homelessness', Social Justice, 30, 195-221.

Bachrach, P. and Baratz, M. S. (1963), 'Decisions and non-decisions: an analytical framework', American Political Science Review, 57, 641-651.

Baggini, J. (2015), Freedom Regained: The Possibility of Free Will, London: Granta.

Bastalgi, F. (2008), 'Conditionality in public policy targeted to the poor: promoting resilience?' Social Policy and Society, 8, 1, 127-140.

Berlin, I. (1969), Four Essays on Liberty, Oxford: Oxford University Press.

Bothfield, S. and Betzelt, S. (2013), 'How do activation policies affect social citizenship? The issue of autonomy', in Ramia, G., Farnsworth, K., Irving, Z. (eds) Social Policy Review 25: Analysis and Debate in Social Policy, 249-270, Bristol: Policy Press.

Bowpitt, G., Dwyer, P., Sundin, E. and Weinstein, M. (2014), 'Places of sanctuary for 'the undeserving'? Homeless people's day centres and the problem of conditionality', British Journal of Social Work 44, 5, 1251-1267, doi: 10.1093/bjsw/bcs196

Buckingham, H. (2011), 'Hybridity, diversity and the division of labour in the third sector: what can we learn from homelessness organisations in the UK?', Voluntary Sector Review 2, 2, $157-175$.

Busch-Geertsema, V. (2013), Housing First Europe: Final Report, Bremen/Brussels: Housing First Europe.

Caplan, A. (2008), 'Denying autonomy in order to create it: the paradox of forcing treatment upon addicts', Addiction, 103, 1919-1921, doi:10.1111/j.1360-0443.2008.02369.x

Cloke, P., May, J. and Johnsen, S. (2005), 'Exploring ethos? Discourses of 'charity' in the provision of emergency services for homeless people', Environment and Planning A, 37, $385-402$.

Cloke, P., May, J. and Johnsen, S. (2010), Swept Up Lives? Re-envisioning the homeless city, Oxford: Wiley-Blackwell.

Deacon, A. (2004), 'Justifying conditionality: the case of anti-social tenants', Housing Studies, 19, 6, 911-926.

Deci, E. L. and Ryan, R. M. (2008), 'Self-determination theory: A macrotheory of human motivation, development, and health', Canadian psychology/Psychologie canadienne, 49, 3, $182-185$. 
DeVerteuil, G., May, J. and von Mahs, J. (2009), 'Complexity not collapse: recasting the geographies of homelessness in a 'punitive' age', Progress in Human Geography, 33, 5, 646-666.

DeVerteuil, G. (2014), 'Does the punitive need the supportive? A sympathetic critique of current grammars of urban injustice', Antipode, 46, 4, 874-893.

Dobson, R. (2011), 'Conditionality and homelessness services: "practice realities" in a drop-in centre', Social Policy and Society, 10, 4, 547-57.

Dobson, R. (2015), 'Power, Agency, Relationality and Welfare Practice', Journal of Social Policy, 44, 4, 687-705, doi: 10.1017/So047279415000318.

Epel, E., Bandura, A. and Zimbardo, P. (1999), 'Escaping homelessness: the influences of selfefficacy and time perspective on coping with homelessness', Journal of Applied Social Psychology, 29, 3, 575-596.

Fernandez Evangelista, G. and Jones, S. (2013), Mean Streets: A Report on the Criminalisation of Homelessness in Europe, Brussels: L'Imprimerie Chauveheid.

Fitzpatrick, S., Bramley, G. and Johnsen, S. (2013), 'Pathways into multiple exclusion homelessness in seven UK cities', Urban Studies, 50, 1, 148-168.

Fitzpatrick, S., Bramley, G., Sosenko, F., Blenkinsopp, J., Johnsen, S., Littlewood, M., Netto, G. and Watts, B. (2016), Destitution in the UK, York: Joseph Rowntree Foundation.

Fitzpatrick, S. and Johnsen, S. (2009), 'The use of enforcement to combat 'street culture' in England: An ethical approach?' Ethics and Social Welfare, 3, 3, 284-302.

Fitzpatrick, S., Johnsen, S. and White, M. (2011), 'Multiple exclusion homelessness in the UK: key patterns and intersections', Social Policy and Society, 10, 4, 501-512.

Fitzpatrick, S. and Jones, A. (2005), 'Pursuing social justice or social cohesion? Coercion in street homelessness policies in England', Journal of Social Policy, 34, 3, 389-406.

Flint, J. (2009), 'Governing marginalised populations: the role of coercion, support and agency', European Journal of Homelessness, 3, 247-260.

Frankfurt, H. G. (1971), 'Freedom of the Will and the Concept of a Person', Journal of Philosophy, $68,1,5-20$.

Goodin, B. (1995), 'In Defence of the Nanny State' in Etzioni, A. (ed.), Rights and the Common Good: Communitarian Perspectives, 125-132, New York: St Martin's Press.

Grant, R. (2002), 'The ethics of incentives: historical origins and contemporary understandings', Economics and Philosophy, 18, 111-139.

Grant, R. (2006), 'Ethics and incentives: a political approach', American Political Science Review, $100,1,29-39$.

Grant, R. (2012), Strings Attached: Untangling the Ethics of Incentives, Princeton: Russel Sage Foundation/Princeton University Press.

Greer, P. and Horst, C. (2014), Mission Drift: The Unspoken Crisis Facing Leaders, Charities, and Churches, Bethany House.

Gregory, J. (2015), 'Engineering compassion: the institutional structure of virtue', Journal of Social Policy, 44, 2, 339-356.

Harris, S. (2012), Free Will, New York: Free Press.

Harrison, M. and Sanders, T. (Eds.) (2016), Social Policies and Social Control: New Perspectives on the 'not-so-big' Society, Bristol: Policy Press.

Higgins, J. (1980), 'Social control theories of social policy', Journal of Social Policy, 9, 1, 1-23.

Housing Justice. (2008), Rough Sleeping: Compassion v Coercion: Church, Community and Government Responses, London: Housing Justice.

Johnsen, S. (2014), 'Where's the 'faith' in 'faith-based' organisations? The evolution and practice of faith-based homelessness services in the UK', Journal of Social Policy, 43, 2, 413-430.

Johnsen, S., Cloke, P. and May, J. (2005a), 'Transitory spaces of care: serving homeless people on the street', Health and Place. 11, 4, 323-336.

Johnsen, S., Cloke, P. and May, J. (2005b), 'Day centres for homeless people: spaces of care or fear?' Social and Cultural Geography, 6, 6, 787-811.

Johnsen, S. and Fitzpatrick, S. (forthcoming), 'Faith, values and metaphysical positionality', in Woodhead, L. (ed), How to Research Religion: Putting Methods Into Practice, Oxford: Oxford University Press. 
Johnsen, S. and Fitzpatrick, S. (2010), 'Revanchist sanitisation or coercive care? The use of enforcement to combat begging, street drinking and rough sleeping in England', Urban Studies, 47, 8, 1703-1723.

Johnsen, S., Watts, B. and Fitzpatrick, S. (2016), First Wave Findings: homelessness. Welfare Conditionality: Sanctions, Support and Behaviour change project, York: University of York.

Johnsen, S. (2016), 'Homelessness, social control and the 'complex needs' conundrum', Paper presented at the Housing Studies Association conference, York, April 6-8.

Jones, R., Pykett, J. and Whitehead, M. (2013), Changing Behaviours: On the Rise of the Psychological State, Cheltenham: Edward Elgar.

Lancione, M. (2014), 'Entanglements of faith: discourses, practices of care and homeless people in an Italian City of Saints', Urban Studies, 51, 14, 3062-3078.

Lukes, S. (2005), Power: A Radical View, Basingstoke, Palgrave Macmillan.

Lunze, K., Idrisov, B., Golichenko, M. and Kamarulzaman, A. (2016), 'Mandatory addiction treatment for people who use drugs: global health and human rights analysis', $B M J 353$, 2943, 1-5, doi: 10.1136/bmj.i2943

McNaughton Nicholls, C. (2009), 'Agency, transgression and the causation of homelessness: A contextualised rational action analysis', European Journal of Homelessness, 9, 1, 69-84.

McNaughton Nicholls, C. (2010), 'Housing, Homelessness and Capabilities', Housing, Theory and Society, 27, 1, 23-41.

Midgley, J. (2016), 'Perspectives on responsibility in practice as revealed through food provisioning offers for rough sleepers', Critical Social Policy, 36, 4, 610-629.

Mill, J. S. (1860), On Liberty, London: John W.Parker \& Son.

Mitchell, D. (1997), 'The annihilation of space by law: the roots and implications of antihomelessness laws in the United States', Antipode, 29, 303-336.

Morrison, D. (2009), 'Homelessness as an independent risk factor for mortality: results from a retrospective cohort study', International Journal of Epidemiology, 38, 877-883.

Nagel, T. (1979), 'The fragmentation of value' in Mortal Questions, 128-141, Cambridge: Cambridge University Press.

NLCHP. (2014), No Safe Place: The Criminalization of Homelessness in U.S. Cities, NLCHP.

New, B. (1999), 'Paternalism and public policy', Economics and Philosophy, 15, 1, 63-83.

Nussbaum, M. (1992), 'Human functioning and social justice: in defence of Aristotelian essentialism', Political Theory, 20, 2, 202-246.

Nussbaum, M. C. (2000), Women and Human Development: The Capabilities Approach, Cambridge, UK: Cambridge University Press.

O'Sullivan, E. (2012), 'Varieties of punitiveness in Europe: homelessness and urban marginality', European Journal of Homelessness, 6, 2, 69-97.

Parsell, C. (2011), 'Responding to people sleeping rough: dilemmas and opportunities for social work', Australian Social Work 64, 3, 330-345.

Parsell, C., Fitzpatrick, S. and Busch-Geertsema, V. (2014), 'Common Ground in Australia: An object lesson in evidence hierarchies and policy transfer', Housing Studies, 29, 1, 69-87.

Parsell, C. and Marston, G. (2016), 'Supportive housing: justifiable paternalism?' Housing, Theory and Society, 33, 2, 195-216.

Randall, G. and Brown, S. (2002), Helping rough sleepers off the streets: A report to the Homelessness Directorate, London: ODPM.

Scanlon, C. and Adlam, J. (2008), 'Refusal, social exclusion and the cycle of rejection: A cynical analysis', Critical Social Policy, 28, 4, 529-549.

Sen, A. (1992), Inequality Re-examined, New York: Russell Sage Foundation.

Shelter. (2005), Food for thought: soup-runs and soup kitchens, Shelter: London.

Smith, N. (1996), The New Urban Frontier: Gentrification and the Revanchist City, New York: Routledge.

Spicker, P. (1984), Stigma and Social Welfare, Beckenham: Croom Helm.

Stuart, F. (2014), 'From 'Rabble Management' to 'Recovery Management': Policing Homelessness in Marginal Urban Space', Urban Studies, 51, 9, 1909-1925. doi: 0042098013499798 . 
Sullivan, E., Harris, A. and Pfefferbaum, A. (2010), 'Alcohol's effects on brain and behavior', Alcohol Research and Health, 33, 1-2, 127-143.

Tanekenov, A., Fitzpatrick, S. and Johnsen, S. (2017), 'Empowerment, capabilities and homelessness: the limitations of employment-focused social enterprises in addressing complex needs', Housing, Theory \& Society, doi: 10.1080/14036096.2017.1290676.

Thomas, M. and L. Buckmaster. (2010), Paternalism in Social Policy: When is It Justifiable? Canberra: Parliament of Australia.

Titmuss, R. (1997), The Gift Relationship, New York: The New York Press.

Wahab, S. (2005), 'Motivational interviewing and social work practice', Journal of Social Work, $5,1,45-60$.

Walter, Z.C., Jetten, J. Dingle, G.A., Parsell, C. and Johnstone, M. (2016), 'Two pathways through adversity: Predicting well-being and housing outcomes among homeless service users', British Journal of Social Psychology, 55, 357-374.

Watts, B. and Fitzpatrick, S. (forthcoming), Key Ideas: Welfare Conditionality. London: Routledge.

Watts, B. (2014), 'Homelessness, empowerment and self-reliance in Scotland and Ireland: the impact of legal rights to housing for homeless people', Journal of Social Policy, 43, 4, 793-810, doi: 10.1017/Soo47279414000282.

Webb, P. (2014), Homeless Lives in American Cities: Interrogating Myth and Locating Community, New York: Palgrave Macmillan.

White, S. (2003), The Civic Minimum: On the Rights and Obligations of Economic Citizenship, Oxford: Oxford University Press.

Whiteford, M. (2010), 'Hot tea, dry toast and the responsibilisation of homeless people', Social Policy and Society, 9, 2, 193-205.

Williamson, T. (2002), 'Ethics of assertive outreach (assertive community treatment teams)', Current Opinion in Psychiatry, 15, 543-547. 